Wind Energ. Sci. Discuss., https://doi.org/10.5194/wes-2018-29

Manuscript under review for journal Wind Energ. Sci.

Discussion started: 14 May 2018

(c) Author(s) 2018. CC BY 4.0 License.

(c) (i)

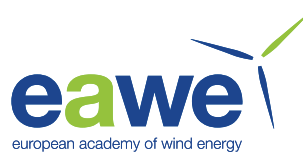

\title{
Control-oriented Linear Dynamic Wind Farm Flow and Operation Model
}

\author{
Jonas Kazda ${ }^{1}$ and Nicolaos Antonio Cutululis ${ }^{1}$ \\ ${ }^{1}$ DTU Wind Energy
}

Correspondence: Jonas Kazda (kazd@dtu.dk)

\begin{abstract}
.
The use of dynamic wind farm flow models is beneficial for power reference following wind farm control. However, currently investigated flow models are non-linear and computationally expensive, while common control approaches require fast, linear models. This work presents a novel wind farm operation modelling approach named the Dynamic Flow Predictor. The Dynamic Flow Predictor was developed with the objective to provide predictions of wind speed and turbine power using a computationally effective, linear, dynamic state space model. The model estimates wind turbine aerodynamic interaction using a linearized engineering wake model in combination with a delay process. Simulations of two turbines and eight turbines in SimWindFarm show that the Dynamic Flow Predictor can provide accurate estimates and predictions of wind turbine rotor effective wind speed and power. Additionally, the Dynamic Flow Predictor is computationally effective as it requires only 5\% of the states of a comparable, dynamic 2D CFD model. The presented modelling approach is thus well suited for the use in wind farm control, while it is envisioned that the model can also be useful for wind turbine control and as a virtual wind turbine sensor.
\end{abstract}

\section{Introduction}

The turbulent nature of wind farm flow (Crespo and Hernández, 1996) drives the need for predicting wind speed dynamics at wind turbines in wind farm control and wind turbine control. Therefore investigated prediction approaches for wind farm control and wind turbine control are individual turbine-focused prediction methods (Riverso et al., 2017; Mikkelsen et al., 2013; Schlipf et al., 2013) and wind farm-scale, dynamic flow models (Boersma et al., 2016; Soleimanzadeh et al., 2014). These prediction approaches differ in the targeted prediction horizon. Whereas individual turbine-focused prediction methods typically aim to predict up to $1 \mathrm{~min}$ into the future, wind farm-scale flow models target prediction horizons in the order of time-scales of the aerodynamic interaction of wind turbines, that is horizons ranging between $1 \mathrm{~min}$ and $10 \mathrm{~min}$.

Individual turbine-focused prediction approaches use turbine-based measurements or remote sensing in the turbine's proximity to predict the evolution of wind speed at that turbine. The turbine-based or remote sensing measurements are input to a predictor such as statistical models (Riverso et al., 2017; Knudsen et al., 2011) and / or machine learning (Wang and Hu, 2015). An overview of wind speed prediction methods can be found in Jung and Broadwater (2014). Individual turbine-focused pre- 
Wind Energ. Sci. Discuss., https://doi.org/10.5194/wes-2018-29

Manuscript under review for journal Wind Energ. Sci.

Discussion started: 14 May 2018

(c) Author(s) 2018. CC BY 4.0 License.

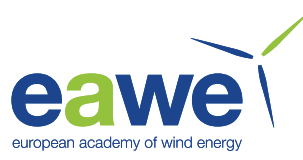

diction methods do, however, not consider the effect of wind turbine operation on the aerodynamic interaction of wind turbines. The aerodynamic interaction of wind turbines is explicitly modelled in wind farm-scale flow models.

The modelling of aerodynamic interaction effects is beneficial in certain areas of wind farm control. Wind farm control approaches with the objective to maximize total wind farm power typically use static wind farm-scale flow models (Gebraad and van Wingerden, 2014b; Kazda et al., 2016a). Shapiro et al. (2018) showed that the use of dynamic wind farm-scale flow models is beneficial in power reference following wind farm control. Control-oriented, dynamic wind farm flow models are usually based on either engineering wake models (Gebraad and van Wingerden, 2014a; Göçmen et al., 2016; Shapiro et al., 2018) or two-dimensional computational fluid dynamics (CFD) (Boersma et al., 2016; Soleimanzadeh et al., 2014). The investigated, engineering wake model-based wind farm flow models are non-linear and thus unsuited for the use in linear control approaches. The two-dimensional CFD approaches model hub height wind farm flow using simplified, two-dimensional Navier-Stokes equations. However, control systems do not require an estimate of wind speed covering the entire hub height plane in a wind farm. Wind farm control and wind turbine control approaches typically only require an estimate of wind speed at the location of wind turbines.

Therefore, we developed a computationally effective, dynamic, linear wind farm flow model, the Dynamic Flow Predictor, that provides wind speed estimates only at the control-related locations, that is wind turbines and potentially remote sensing locations. The model is designed using a linear state space approach in order to allow for its application in a wide range of linear control areas.

In the next section, the methodology is detailed. The performance of the model is discussed in two case studies, thereafter. The paper concludes with a summary of the key findings.

\section{Methods}

The newly developed Dynamic Flow Predictor and the simulation environment used for testing the model are described in the following.

\subsection{Dynamic Flow Predictor}

The developed Dynamic Flow Predictor is a linear, dynamic wind farm operation model build as a combination of multiple sub-models in order to enable flexibility in its application. Figure 1 shows the model's system structure, which consists of a flow model and a turbine power model, which are introduced in the following.

\subsubsection{Flow model}

The flow model consists of a set of modules, where each module accounts for the interaction of one or multiple upstream turbines and a single downstream turbine. These interaction models are joined together to a total flow model according to 
Wind Energ. Sci. Discuss., https://doi.org/10.5194/wes-2018-29

Manuscript under review for journal Wind Energ. Sci.

Discussion started: 14 May 2018

(c) Author(s) 2018. CC BY 4.0 License.

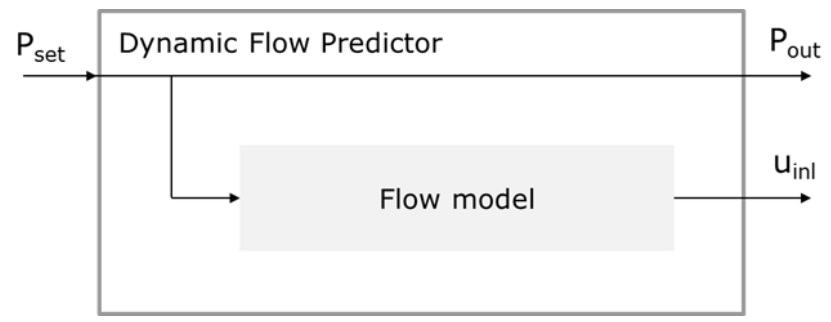

Figure 1. System structure of Dynamic Flow Predictor.

the overall aerodynamic interaction of the wind turbines in the wind farm. The aerodynamic interaction of one or multiple upstream turbines with a downstream turbine is modelled as

$u_{i}(t)=u_{\infty}\left(t-\delta t_{\infty}\right)-\sum_{l=1}^{L_{i}} \delta \tilde{u}_{l}\left(t-\delta t_{l}\right)$

where $u_{i}$ is the inlet wind speed of downstream turbine $i$ at time $t, u_{\infty}$ is the wind speed at the most upstream turbine and

$5 \delta \tilde{u}_{l}$ is the wake deficit induced by upstream turbine $l . L_{i}$ is the number of turbines upstream of turbine $i$. $\delta t_{\infty}$ is the duration for the wake from the most upstream turbine to propagate to downstream turbine $i . \delta t_{l}$ is the duration for the wake from upstream turbine $l$ to propagate to downstream turbine $i$. The duration of wake propagation duration is determined using an engineering model (Machefaux et al., 2015). The aim is to choose the model that matches the considered wind farm as close as possible. In SimWindFarm the wake propagation speed is proportional to freestream flow. Thus, the wake propagation delay $\delta t$ in this work is calculated as $\delta t=\delta x / u$, where $u$ is the measured wind speed and $\delta x$ the distance of the propagated wake.

The wake deficit is modelled based on the Frandsen wake model (Frandsen et al., 2006). The model is chosen as the same wake deficit model is used in the simulation environment, but other wake models can be used similarly. Given the multitude of wake deficit models available in literature, the aim is generally to choose the model that matches the considered wind farm as close as possible. The linearized wake deficit is obtained from the $1^{\text {st }}$ order Taylor series expansion of the wake deficit model as

$\delta \tilde{u}_{l}=\delta u_{l, 0}+\left.\frac{\partial \delta u_{l}}{\partial u_{l}}\right|_{x_{0}} \Delta u_{l}+\left.\frac{\partial \delta u_{l}}{\partial P_{l}}\right|_{x_{0}} \Delta P_{l}$

where $\Delta u_{l}$ is the deviation of $u_{l}$ from the wind speed linearization point $u_{l, 0}, \Delta P_{l}$ denotes the deviation of turbine power $P_{l}$ from the power linearization point $P_{l, 0}$, and $x_{0}$ is the overall system linearization point.

The Dynamic Flow Predictor is a discrete time model and thus the aerodynamic interaction of wind turbines (Eq. 1) is converted to

$u_{i}[n]=u_{\infty}\left[n-\kappa_{\infty}\right]-\sum_{l=1}^{L_{i}} \delta \tilde{u}_{l}\left[n-\kappa_{l}\right]$ 
Wind Energ. Sci. Discuss., https://doi.org/10.5194/wes-2018-29

Manuscript under review for journal Wind Energ. Sci.

Discussion started: 14 May 2018

(c) Author(s) 2018. CC BY 4.0 License.

where $n$ is the discrete time step with $t=n * T_{s}$ and $T_{s}$ the sampling time. Sampling times used with the Dynamic Flow Predictor are in the order of $10 \mathrm{~s}$. The discrete time delay $\kappa$ is defined as $\kappa=\left(\delta t / T_{s}\right)_{\text {round }}$.

After converting Eq. (3) to state space form and joining all wake interaction processes, the total wind farm flow model can be written as

$5 \quad\left[\begin{array}{c}\boldsymbol{u}_{\text {del, all }} \\ \boldsymbol{u}_{0}\end{array}\right][n+1]=\left[\begin{array}{cc}\mathbf{A}_{\text {del,all }}+\mathbf{B}_{u, \text { all }} \mathbf{C}_{u} & \mathbf{B}_{u_{0}, \text { all }} \\ 0 & \mathbf{I}\end{array}\right]\left[\begin{array}{c}\boldsymbol{u}_{\text {del, all }} \\ \boldsymbol{u}_{0}\end{array}\right][n]+\left[\begin{array}{c}\mathbf{B}_{\Delta P, \text { all }} \\ 0\end{array}\right] \Delta \boldsymbol{P}[n]$

$\boldsymbol{u}[n]=\left[\begin{array}{ll}\mathbf{C}_{u} & 0\end{array}\right]\left[\begin{array}{c}\boldsymbol{u}_{\text {del, all }} \\ \boldsymbol{u}_{0}\end{array}\right][n]$

$\boldsymbol{u}_{d e l, a l l}$ is the rotor effective wind speed delay states of all wind turbines, $\boldsymbol{u}_{0}$ is the wind speed linearization point and $\boldsymbol{u}$ is the present rotor effective wind speed at the turbines in the wind farm. $\Delta \boldsymbol{P}$ is the deviation of the turbine power set-points from the power linearization point.

$\boldsymbol{x}[n+1]=\mathbf{A} \boldsymbol{x}[n]+\mathbf{B} \boldsymbol{u}[n]$

$\boldsymbol{u}[n]=\mathbf{C}_{u, t o t} \boldsymbol{x}[n]$

where $\boldsymbol{x}$ is the state vector and $\boldsymbol{u}$ is the control input vector. $\mathbf{A}$ and $\mathbf{B}$ are system process matrices and $\mathbf{C}_{u}$ is the wind speed output matrix.

\subsubsection{Turbine operation model}

As shown in Figure 1 above, turbine power is modelled using a direct feed-through. As such the modelled turbine power output equals the turbine power set-point. This assumption is valid if the sampling time is much larger than the turbine generator dynamics. Generator dynamics are typically in the order of seconds. The smallest sampling time considered for the Dynamic Flow Predictor is 30s.

\subsection{Kalman filter and system update}

To improve the prediction accuracy of the Dynamic Flow Predictor, an ordinary Kalman filter (Kalman and Bucy, 1961) is employed. As shown in Figure 2, the model update process is structured into three steps: (1) Time update, (2) data update and (3) system matrix update. 
Wind Energ. Sci. Discuss., https://doi.org/10.5194/wes-2018-29

Manuscript under review for journal Wind Energ. Sci.

Discussion started: 14 May 2018

(c) Author(s) 2018. CC BY 4.0 License.

(c) (i)
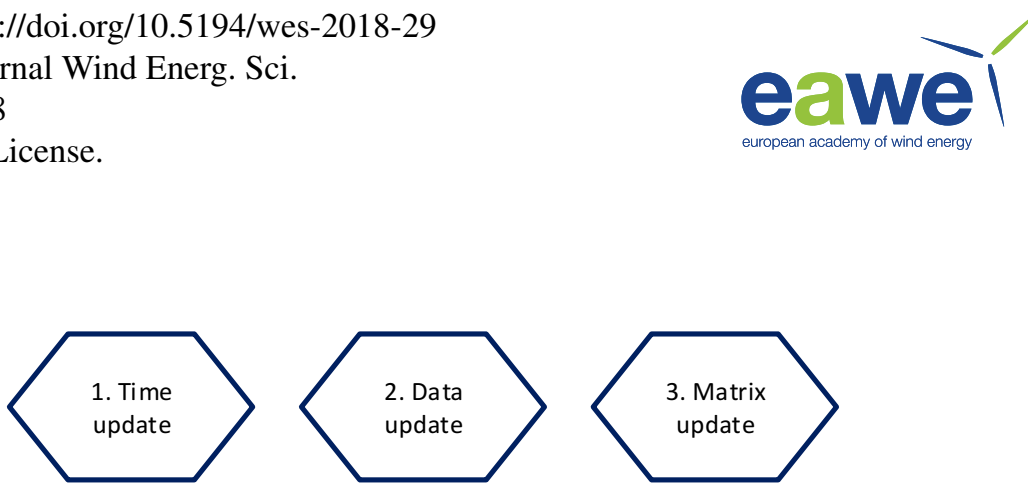

Figure 2. Process of system update using ordinary Kalman filter and time-variant system matrices.

\subsubsection{Time update}

First, in the time update of the Kalman filter the state estimate from the prior time step $n-1$ is used to predict the current system state at time step $n$ based on the system model of time step $n-1$. The time update is calculated as

$\left.\hat{\boldsymbol{x}}\right|_{n-1}[n]=\left.\left.\mathbf{A}\right|_{n-1} \hat{\boldsymbol{x}}\right|_{n-1}[n-1]+\left.\mathbf{B}\right|_{n-1} \boldsymbol{u}[n-1]$

where $\left.\hat{\boldsymbol{x}}\right|_{n-1}$ is the state estimate condition to measurements up to time step $n-1$. Similarly, $\left.\mathbf{A}\right|_{n-1}$ and $\left.\mathbf{B}\right|_{n-1}$ are system matrices at time step $n-1$. The variance of the state estimate, $\mathbf{P}$, is updated as

$\left.\mathbf{P}\right|_{n-1}[n]=\left.\left.\left.\mathbf{A}\right|_{n-1} \mathbf{P}\right|_{n-1}[n-1] \mathbf{A}^{T}\right|_{n-1}+\left.\mathbf{R}_{1}\right|_{n-1}$

where $\mathbf{R}_{1}$ is the variance of the process error.

\subsubsection{Data update}

10 Second, in the data update of the Kalman filter the system state is updated with present system measurements, that are related to system states as

$\boldsymbol{y}_{\text {meas }}[n]=\left.\mathbf{C}_{\text {meas }}\right|_{n-1} \boldsymbol{x}[n]$

The Kalman gain $\kappa$ is calculated as

$\left.\kappa\right|_{n}=\left.\left.\mathbf{P}\right|_{n-1}[n] \mathbf{C}_{\text {meas }}^{T}\right|_{n-1}\left(\left.\left.\left.\mathbf{C}_{\text {meas }}\right|_{n-1} \mathbf{P}\right|_{n-1}[n] \mathbf{C}_{\text {meas }}^{T}\right|_{n-1}+\left.\mathbf{R}_{2}\right|_{n-1}\right)^{-1}$

where $\mathbf{R}_{2}$ is the variance of the measurement noise. The data update is performed as

$\left.\hat{\boldsymbol{x}}\right|_{n}[n]=\left.\hat{\boldsymbol{x}}\right|_{n-1}[n]+\left.\kappa\right|_{n}\left(\boldsymbol{y}_{\text {meas }}[n]-\left.\left.\mathbf{C}_{\text {meas }}\right|_{n-1} \hat{\boldsymbol{x}}\right|_{n-1}[n]\right)$

$\left.\mathbf{P}\right|_{n}[n]=\left.\mathbf{P}\right|_{n-1}[n]-\left.\left.\left.\left.\mathbf{P}\right|_{n-1}[n] \mathbf{C}_{\text {meas }}^{T}\right|_{n-1}\left(\left.\left.\left.\mathbf{C}_{\text {meas }}\right|_{n-1} \mathbf{P}\right|_{n-1}[n] \mathbf{C}_{\text {meas }}^{T}\right|_{n-1}+\left.\mathbf{R}_{2}\right|_{n-1}\right)^{-1} \mathbf{C}_{\text {meas }}\right|_{n-1} \mathbf{P}\right|_{n-1}[n]$ 
Wind Energ. Sci. Discuss., https://doi.org/10.5194/wes-2018-29

Manuscript under review for journal Wind Energ. Sci.

Discussion started: 14 May 2018

(c) Author(s) 2018. CC BY 4.0 License.

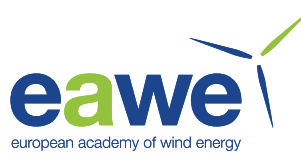

\subsubsection{Matrix update}

Third, system matrices are updated based on the current system operation point. The update approach depends on the deviation of the current system state from the linearization point. If the deviation exceeds the update limit $\epsilon_{\text {upd }}$ the system matrices are updated and as a result the new linearization point equals the current system state. If the deviation is within the limits the system matrices remain unchanged. Consequently, a matrix update is performed if the following condition is satisfied.

$\epsilon_{\text {upd }}<\frac{\left|x-x_{0}\right|}{x_{0}}$

where $\epsilon_{u p d}$ is the update limit, $x$ represents a relevant system condition such as wind conditions and turbine operation point, and $x_{0}$ the linearization point of that condition.

\subsection{SimWindFarm simulation environment}

The Dynamic Flow Predictor is tested in simulations using the dynamic simulation framework SimWindFarm (Grunnet et al., 2010, 2016). SimWindFarm performs simultaneous, dynamic simulations of the wind turbines in the wind farm, the wind farm control, the aerodynamic interaction of the wind turbines and the actions by the transmission system operator. The NREL5MW virtual turbine model (Jonkman et al., 2009) is used to model wind turbine operation. Wind turbine aerodynamics are modelled using the turbine power coefficient and thrust coefficient. Up to 3rd order dynamic models are employed to simulate the drive train, generator and pitch actuator. The aerodynamic model of the wind flow in the wind farm is structured into an ambient field model and a turbine wake model part. The ambient wind field is modelled as the hub height, turbulent wind flow advected with the mean wind speed under the assumption of Taylor's frozen turbulence. Wake flow modelling includes wake wind speed deficit, wake width expansion, wake meandering and wake merging. Wind turbines are controlled using the DTU Wind Farm Controller (Kazda et al., 2016b), which is linked to the SimWindFarm simulation tool and replaces the basic, standard wind farm controller in SimWindFarm.

All simulations use the same wind conditions and a turbine spacing of 4.3D. The simulated wind conditions have a mean wind speed of $8 \mathrm{~m} / \mathrm{s}$, a turbulence intensity of $6 \%$. The wind direction is considered aligned with the turbine row, if not indicated differently in the discussion.

\section{Results \& Discussion}

25 The performance of the Dynamic Flow Predictor is assessed in a two turbine and an eight turbine case study. The aim of the two turbine case study is to showcase the performance, robustness and validity of the modelling approach. In the eight turbine case study, the model's performance is analyzed with respect to the model's application in wind farms. 
Wind Energ. Sci. Discuss., https://doi.org/10.5194/wes-2018-29

Manuscript under review for journal Wind Energ. Sci.

Discussion started: 14 May 2018

(c) Author(s) 2018. CC BY 4.0 License.

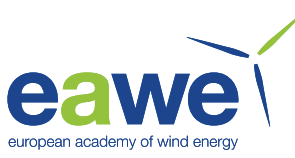

\subsection{Two turbine case study}

In the following, first, the simulation set-up is introduced, second, the simulated wind farm operation scenario is presented, and third, the performance, robustness and validity of the model is discussed with respect to Kalman filtering, model update and wind direction.

\section{3.1.1 Simulation set-up}

The case study is performed in the dynamic simulation tool SimWindFarm. The layout of the simulated two turbine array is shown in Figure 3. As such turbine No. 1 is the upstream turbine and turbine No. 2 the downstream turbine.

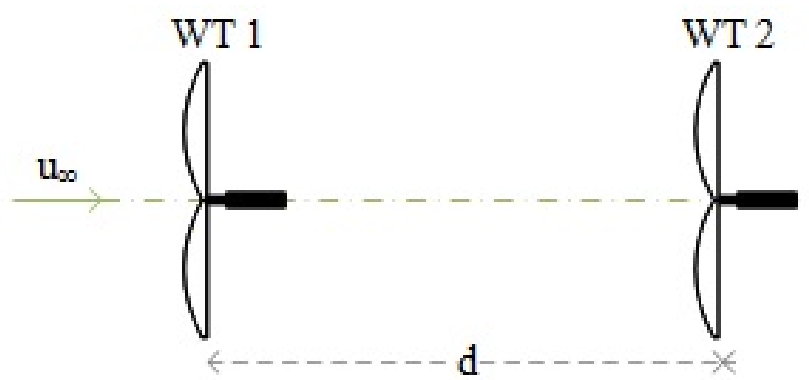

Figure 3. Layout of two turbine array used for test of Dynamic Flow Predictor.

\subsubsection{Wind farm operation}

The present design of the Dynamic Flow Predictor targets the prediction of wind farm flow and operation with the objective to follow a total power reference signal. The model tests are thus conducted in power reference following operation in both case studies. Both case studies use the same normalized total power reference signal, which is used in the wind farm ancillary service balance control. The total power reference signal is further chosen as such that the resulting individual turbine power references never exceed a turbine's available power in any of both case studies. The limiting turbine in terms of available power is the most downstream turbine of the eight turbine array, as can be seen in Figure 4.

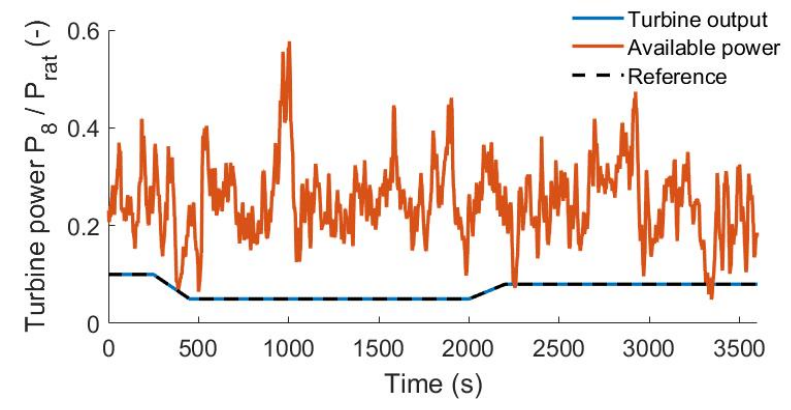

Figure 4. Simulated power output of most downstream turbine No. 8 of eight turbine array. 
Wind Energ. Sci. Discuss., https://doi.org/10.5194/wes-2018-29

Manuscript under review for journal Wind Energ. Sci.

Discussion started: 14 May 2018

(c) Author(s) 2018. CC BY 4.0 License.

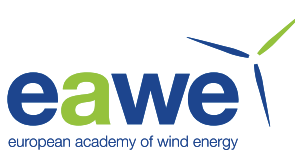

Figure 5.a shows the simulated total farm power output, the total power reference signal and the wind farm available power for the two turbine case study. The power is normalized with the rated wind farm power. The wind farm is controlled using the DTU Wind Farm Controller's closed-loop PI-controller with the equal dispatch function (Kazda et al., 2018) in both case studies. It can be observed, that the total farm power follows the total power reference well. The normalized root-mean-square deviation from the reference is $0.35 \%$. Figure $5 . \mathrm{b}$ shows the simulated dynamics of the blade pitch angle of the wind turbines. The observed variation of the pitch angle results in a variation of the turbine's thrust and consequently, also in a variation of the wake deficit generated by that turbine.

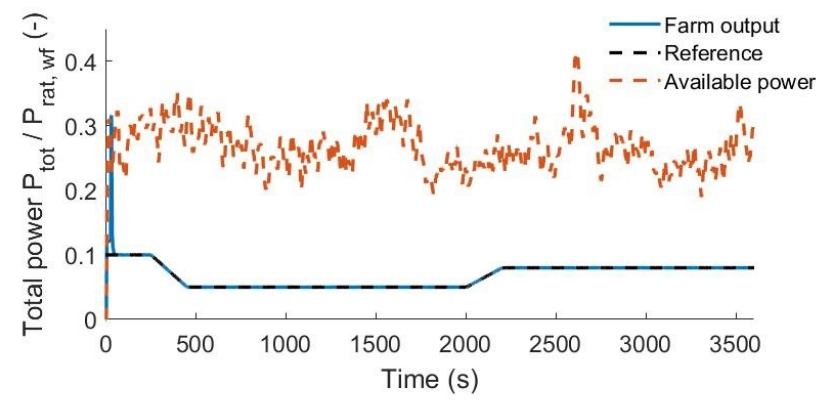

a)

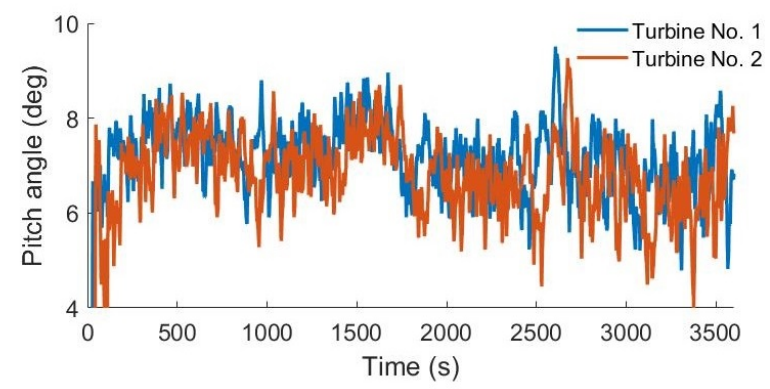

b)

Figure 5. Simulated operation of two turbine array used for comparison with Dynamic Flow Predictor. Shown are (a) total farm power and (b) blade pitch angle.

\subsubsection{Benefits of Kalman filtering}

In Figure 6 the turbines' rotor effective wind speed estimated by the Dynamic Flow Predictor is compared to the SimWindFarm flow model. Figure 6.a shows the wind speed at upstream turbine No. 1. It can be observed that the wind speed prediction by the Dynamic Flow Predictor is in good agreement with SimWindFarm. The normalized root-mean-square (RMS) deviation of the wind speed prediction of the Dynamic Flow Predictor is $4.8 \%$ both with and without the use of the Kalman filter. It is evident that there is a time lag of one time step in the wind speed estimates of the Dynamic Flow Predictor both with and without the use of the Kalman filter. This is due to the definition of the wind speed state in the Dynamic Flow Predictor. The wind speed state at a time step $n$ is defined as the mean wind speed over the time interval $\left[n T_{s},(n+1) T_{s}\right]$. The wind speed at 
Wind Energ. Sci. Discuss., https://doi.org/10.5194/wes-2018-29

Manuscript under review for journal Wind Energ. Sci.

Discussion started: 14 May 2018

(c) Author(s) 2018. CC BY 4.0 License.

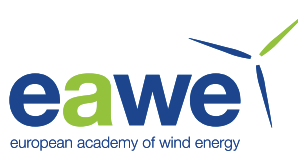

(c) (i)

the upstream turbine at time step $n$ is calculated using a persistence-based prediction from the wind speed measurements over the time interval $\left[(n-1) T_{s}, n T_{s}\right]$. As a result, the Dynamic Flow Predictor wind speed estimate at the upstream turbine has a lag of one time step.

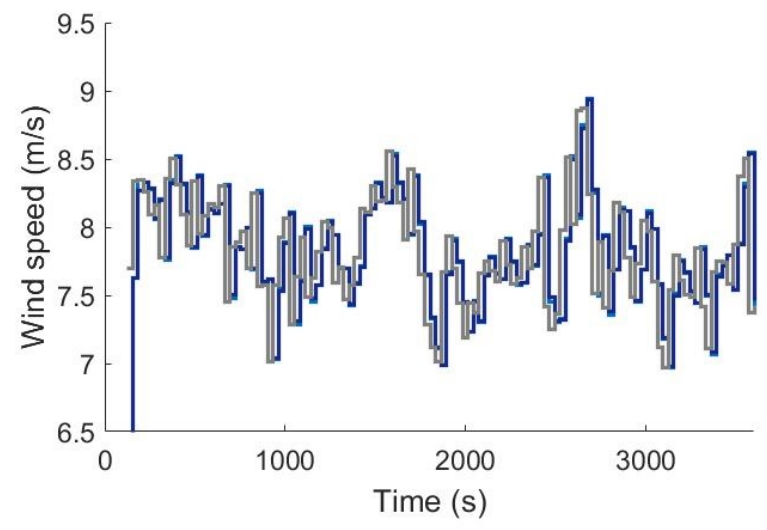

a)

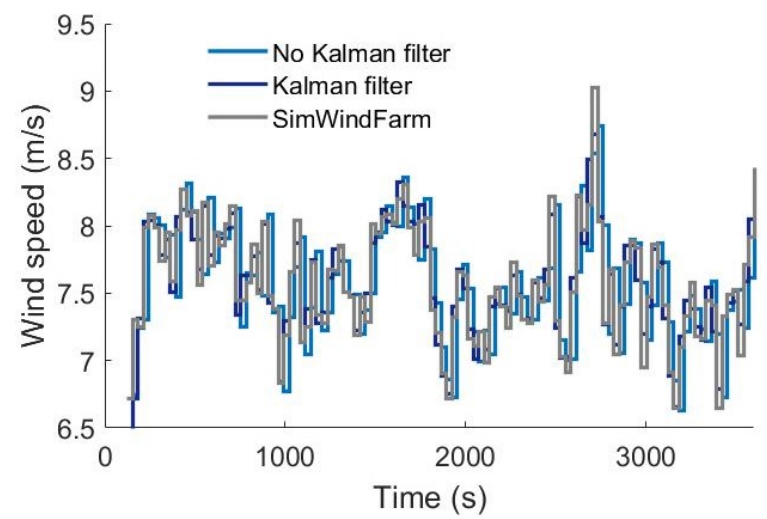

b)

Figure 6. Sampled rotor effective wind speed simulated using SimWindFarm and predicted using Dynamic Flow Predictor with and without use of Kalman filter. Shown are wind speeds of (a) turbine No. 1 and (b) turbine No. 2.

Figure 6.b shows the wind speed at downstream turbine No. 2. It can be observed that the Dynamic Flow Predictor predictions 5 of wind speed are in good agreement with SimWindFarm. The normalized RMS prediction error is $4.4 \%$ without the use of the Kalman filter. The use of the Kalman filter reduces the error by $70 \%$ to a RMS error of only $1.3 \%$, as shown in Figure 7 . The main benefit of using the Kalman filter is that the one step time lag propagating from the upstream turbine is removed and the wake deficit estimation is improved. 
Wind Energ. Sci. Discuss., https://doi.org/10.5194/wes-2018-29

Manuscript under review for journal Wind Energ. Sci.

Discussion started: 14 May 2018

(c) Author(s) 2018. CC BY 4.0 License.

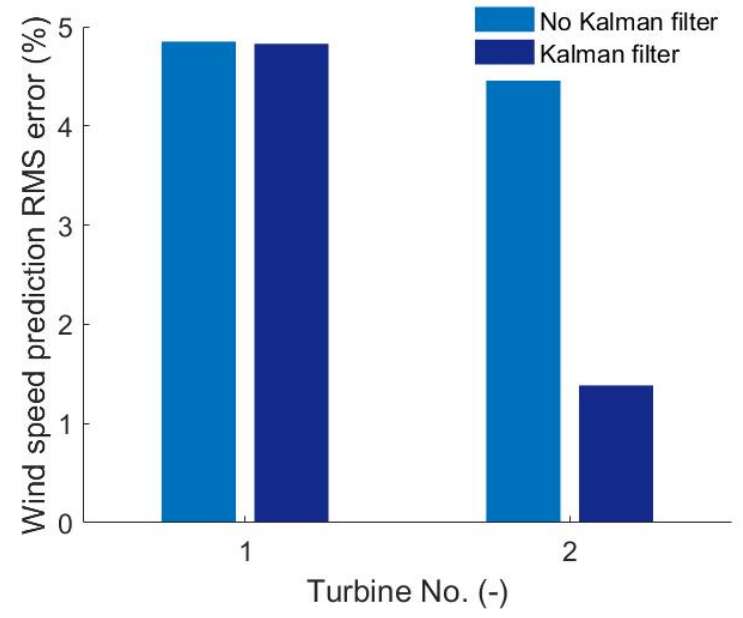

Figure 7. RMS deviation of rotor effective wind speed prediction at turbines of two turbine array. RMS deviation is normalised with mean freestream wind speed.

\subsubsection{Model update frequency}

In the following, we show that the Dynamic Flow Predictor's linearization approach is robust, so model matrix updates are required only seldom. Figure 8 shows the sensitivity of the wind speed estimation accuracy and the model update frequency with respect to the update limit $\epsilon_{\text {upd }}$. The estimation accuracy is the RMS error of rotor effective wind speed at downstream turbine No. 2. The wind speed estimation error at the upstream turbine is not part of this analysis, since it is not dependent on the matrix update. The update frequency is defined as the average ratio of matrix updates $n_{\text {upd }}$ to model iterations $n_{\text {iter }}$. The study is performed without the use of the Kalman filter, so the estimation accuracy is only dependent on the linearization approach.

It can be observed that the linearization approach in the Dynamic Flow Predictor is robust. At least up to an update limit of 0.5 the wind speed prediction accuracy is insensitive to the update limit. An update limit of 0.5 is, for example, a $50 \%$ deviation of wind speed from the wind speed linearisation point. By increasing the update limit from 0.01 to 0.5 , the update frequency decreases from $100 \%$ to $3 \%$. Thus, the update frequency can be reduced by $97 \%$, while estimating wind speed at the same accuracy. The $97 \%$ reduction in the update frequency results in an increased computational effectiveness of the Dynamic Flow Predictor.

It is further estimated that the Dynamic Flow Predictor requires only 5\% of the states of a comparable, dynamic 2D CFD model. This is due to the focus of flow modelling on control-relevant locations. Overall, the Dynamic Flow Predictor is thus expected to be computationally more effective than comparable 2D CFD approaches. 
Wind Energ. Sci. Discuss., https://doi.org/10.5194/wes-2018-29

Manuscript under review for journal Wind Energ. Sci.

Discussion started: 14 May 2018

(c) Author(s) 2018. CC BY 4.0 License.

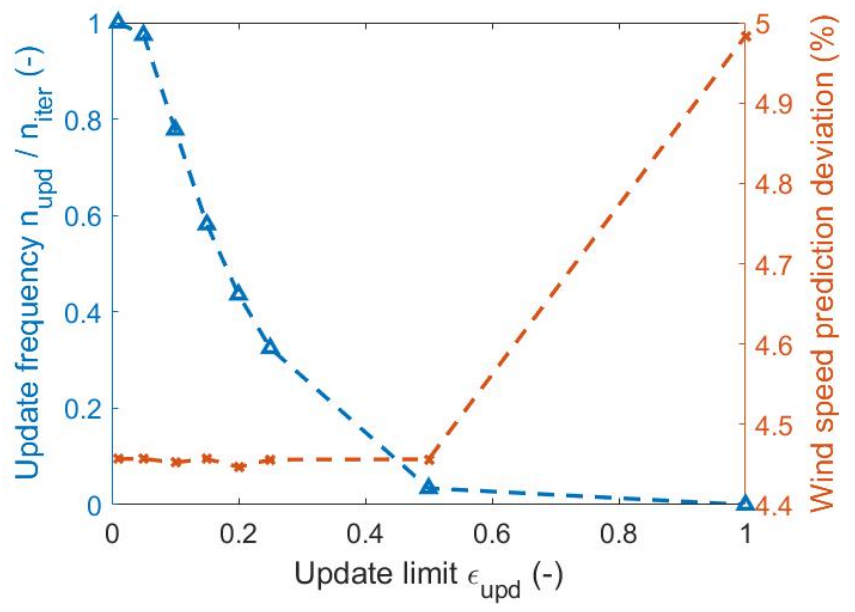

Figure 8. Impact of matrix update limit on downstream turbine wind speed prediction accuracy (right) and matrix update frequency (left).

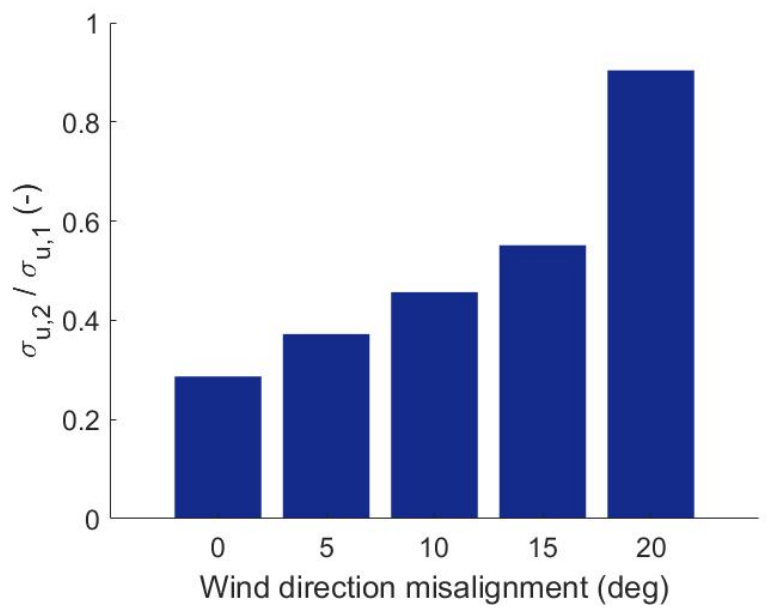

Figure 9. Effect of alignment of turbine array with wind direction on rotor effective wind speed estimation accuracy. Estimation accuracy is ratio of RMS wind speed estimation error at downstream turbine to RMS wind speed estimation error at upstream turbine.

\subsubsection{Effect of wind direction}

The following study shows that the model is suited for the full range of wind directions and wake situations in SimWindFarm. The Dynamic Flow Predictor's accuracy of wind speed prediction is, however, dependent on the alignment of the turbine array with the mean wind direction. Figure 9 shows the effect of the misalignment of the two turbine array with the wind direction 5 on the wind speed estimation accuracy at the downstream turbine. The study is performed with the use of the Kalman filter. The estimation accuracy is the RMS deviation of the Dynamic Flow Predictor wind speed prediction to the SimWindFarm flow 
Wind Energ. Sci. Discuss., https://doi.org/10.5194/wes-2018-29

Manuscript under review for journal Wind Energ. Sci.

Discussion started: 14 May 2018

(c) Author(s) 2018. CC BY 4.0 License.

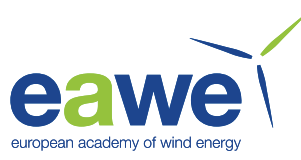

model. The prediction accuracy of the downstream turbine is normalized with the prediction accuracy at the upstream turbine. The simulations show a larger prediction error with an increase in misalignment. With larger misalignment, the correlation of the two turbines' wind speed decreases and thus results in an increasing error of the model. Nonetheless, the error at the downstream turbine is smaller than the persistence-based prediction error at the upstream turbine. At $20^{\circ}$ misalignment the

5 wake from the upstream turbine is not affecting the downstream turbine. Hence, the wind speed estimate at turbine No. 2 is also a persistence-based wind speed estimate. Since both turbines use persistence-based estimates, the ensemble average of the wind speed estimation error is expected to be the same at both turbines. The observed higher prediction accuracy at the downstream turbine is likely to be due to the seed of the turbulent wind field in SimWindFarm.

\subsection{Eight turbine case study}

10 In the eight turbine case study, the performance of the Dynamic Flow Predictor is demonstrated in key areas relevant to the model's application to large wind farms. Given the model's application areas, that is wind farm control, turbine control, and as virtual sensor, the model's performance is analyzed with respect to its accuracy in the prediction of wind speed and available turbine power. An eight turbine array is chosen for the analysis, as it resembles flow interactions present in large wind farms, which can typically be split into rows of turbines, such as the eight turbine array in the present work that is depicted in Figure 1510.

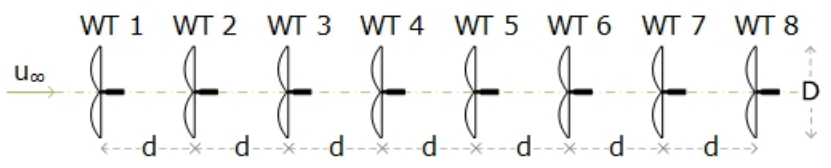

Figure 10. Layout of eight turbine array used for test of Dynamic Flow Predictor.

\subsubsection{Wind speed estimation}

Figure 11 shows the model's accuracy in estimating the rotor effective wind speed of the turbines of the eight turbine array. The accuracy is quantified as the RMS deviation between the model estimations and SimWindFarm. As in the two turbine case study, it is observed that the use of the Kalman filter improves the estimation accuracy. The average improvement is $70 \%$. Without the use of the Kalman filter, the estimation error tends to increase with downstream turbines. This is due to the accumulation of the estimation error with downstream turbines. With the use of the Kalman filter the estimation error ranges from $0.6 \%$ to $3.5 \%$ at downstream turbines. 
Wind Energ. Sci. Discuss., https://doi.org/10.5194/wes-2018-29

Manuscript under review for journal Wind Energ. Sci.

Discussion started: 14 May 2018

(c) Author(s) 2018. CC BY 4.0 License.

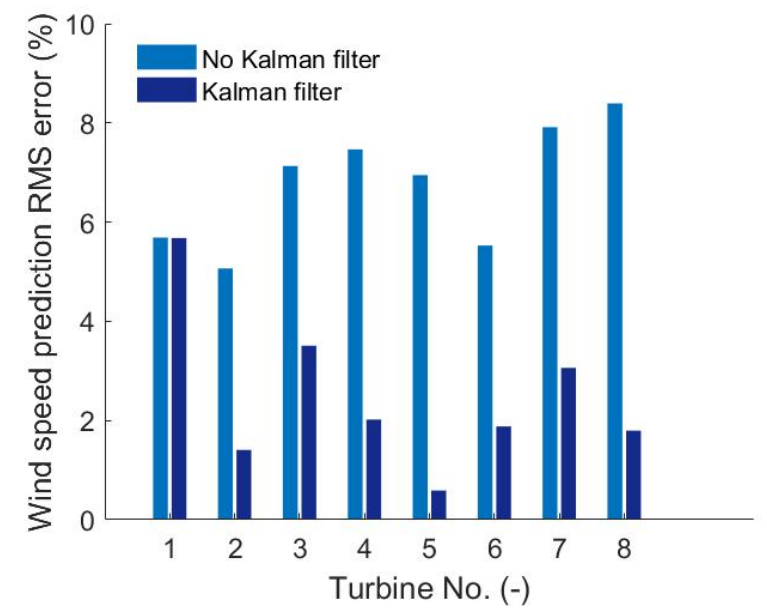

Figure 11. Statistics of prediction accuracy of rotor effective wind speed at turbines of eight turbine array.

\subsubsection{Wind speed prediction}

The analysis of the model's capability for future wind speed prediction shows that the Dynamic Flow Predictor can provide wind speed predictions with an error of less than $4 \%$ over a time horizon of up to $5 \mathrm{~min}$ in this case study. Figure 12 and Figure 13 show the accuracy of the ten-step-ahead prediction of wind speed at the turbines of the eight turbine array. Wind

5 speed predictions are calculated using the state space-driven prediction approach employed in model predictive control. The accuracy is quantified using the RMS difference between the Dynamic Flow Predictor predictions and SimWindFarm. The results shown in Figure 12 are obtained without the use of the Kalman filter. It can be observed that at the downstream turbines the prediction error is close to constant over several prediction steps and then jumps to a higher level of prediction error. The number of steps with close to constant prediction accuracy equals to the number of the model's internal delay states. Further downstream turbines have a longer accurate prediction horizon due to the larger number of internal delay states. Predictions beyond the model's internal delay states are based on persistence and thus less accurate. Future work aims to extend the length of the accurate prediction horizon by exchange the persistence-based wind speed estimate at the upstream turbine with a individual turbine-focused prediction method such as a statistical model as used in (Riverso et al., 2017).

The results in Figure 13 show the same predictions, but obtained with the use of the Kalman filter. The prediction accuracy is improved in the prediction steps, which are based on the model's internal delay states, as compared to the results generated without the use of the Kalman filter. The reduction of the RMS prediction error is on average $71 \%$ as compared to the results generated without the use of the Kalman filter. 
Wind Energ. Sci. Discuss., https://doi.org/10.5194/wes-2018-29

Manuscript under review for journal Wind Energ. Sci.

Discussion started: 14 May 2018

(c) Author(s) 2018. CC BY 4.0 License.
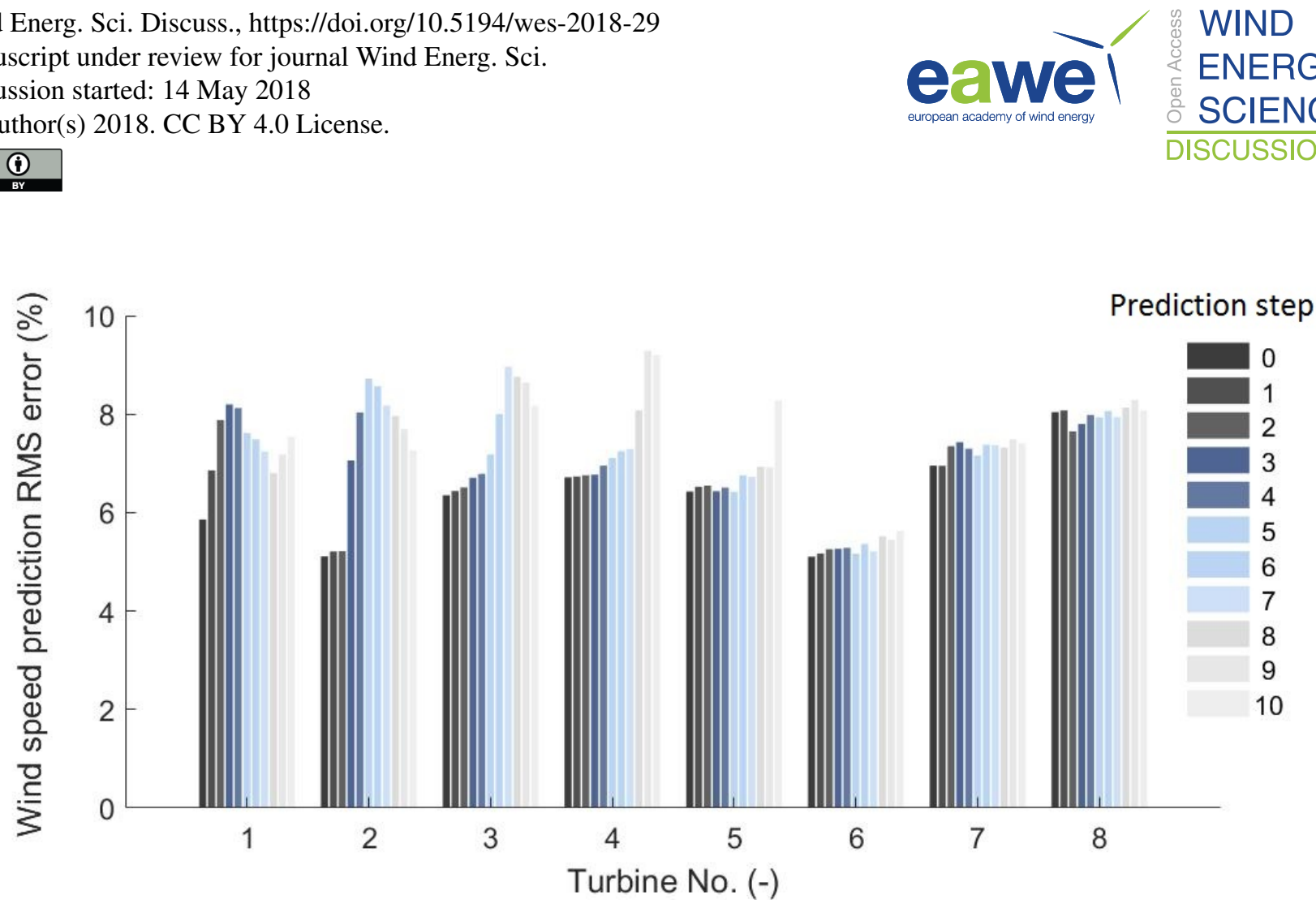

Figure 12. RMS error of 10-step ahead prediction of rotor effective wind speed at turbines of eight turbine array. Prediction is performed by Dynamic Flow Predictor without use of Kalman filter.

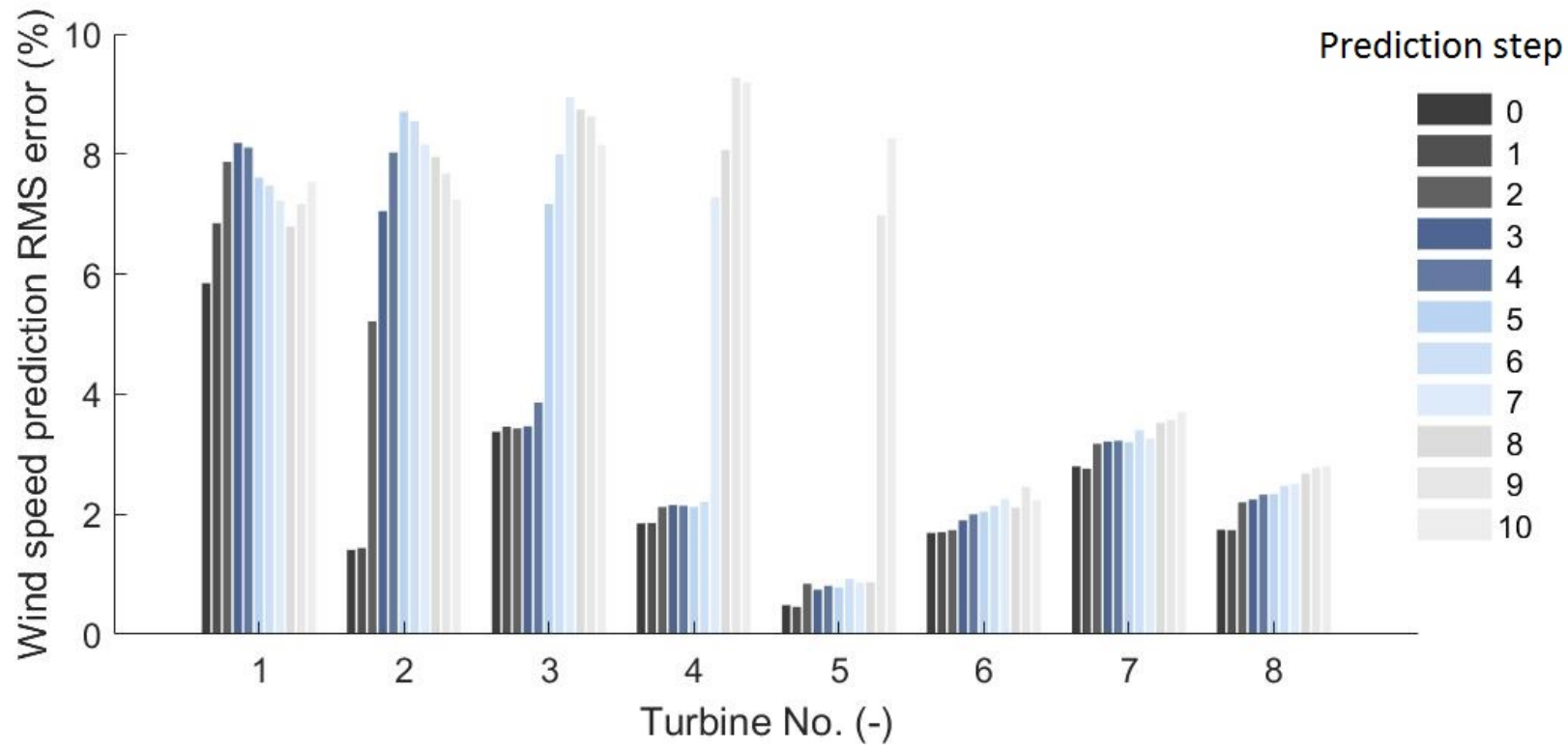

Figure 13. RMS error of 10-step ahead prediction of rotor effective wind speed at turbines of eight turbine array. Prediction is performed by Dynamic Flow Predictor with use of Kalman filter. 
Wind Energ. Sci. Discuss., https://doi.org/10.5194/wes-2018-29

Manuscript under review for journal Wind Energ. Sci.

Discussion started: 14 May 2018

(c) Author(s) 2018. CC BY 4.0 License.

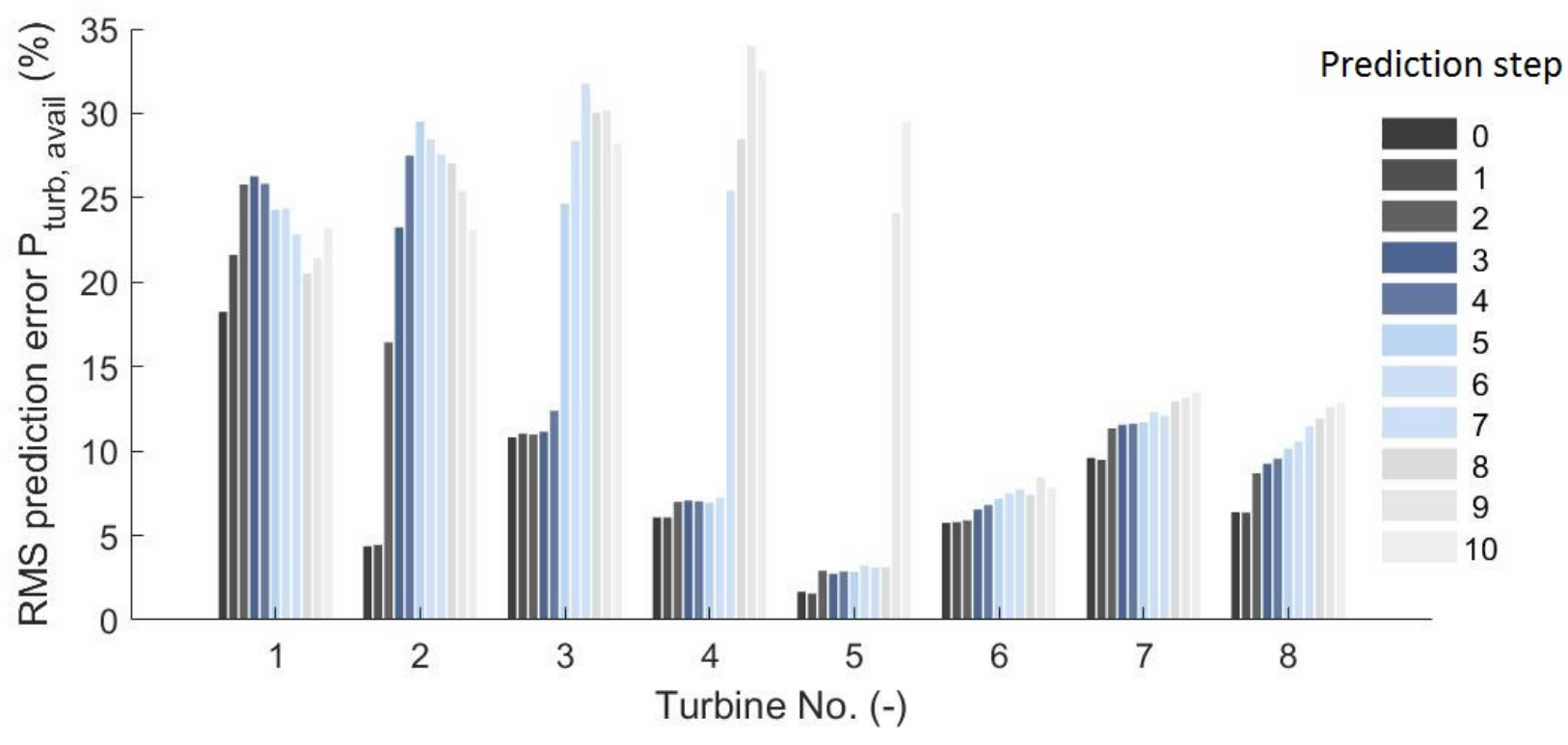

Figure 14. RMS error of 10-step ahead prediction of available power of turbines of eight turbine array.

\subsubsection{Available power prediction}

It is observed that the Dynamic Flow Predictor can predict turbine available power with an error of less than $15 \%$ over a time horizon of up to 5min. Figure 14 shows the RMS error of the prediction of available power at the turbines of the eight turbine array. The available power prediction is calculated using the wind speed predictions obtained from the Dynamic Flow

5 Predictor, including the Kalman filter. The observed pattern in the prediction error is the same as for the wind speed prediction accuracy statistics discussed with Figure 13. The available power predictions that are based on the model's internal delay states show prediction errors ranging from $1.5 \%$ to $14 \%$. The larger error in available power prediction as compared to wind speed prediction is due to the error amplification in the calculation of power from wind speed.

\subsection{Model application areas}

The choice of a linear state space modelling approach enables the application of the Dynamic Flow Predictor in a wide range of control areas. Currently considered application areas of the Dynamic Flow Predictor are (i) wind farm control, (ii) turbine control and (iii) as virtual sensor. In the area of wind farm control, the model can be used in power reference following wind farm control. The model can predict the effect of turbine power set-points on turbine available power over the control horizon. Such predictions are particularly useful in model predictive power reference following wind farm control (Shapiro et al., 2018). In the second application area, turbine control, the model's predictions can be used as input to turbine controllers for an improved predictive control performance. In addition to direct use in control, the model's predictions can be used as a substitute of missing or temporarily unavailable turbine sensors at downstream turbines. 
Wind Energ. Sci. Discuss., https://doi.org/10.5194/wes-2018-29

Manuscript under review for journal Wind Energ. Sci.

Discussion started: 14 May 2018

(c) Author(s) 2018. CC BY 4.0 License.

(c) (i)

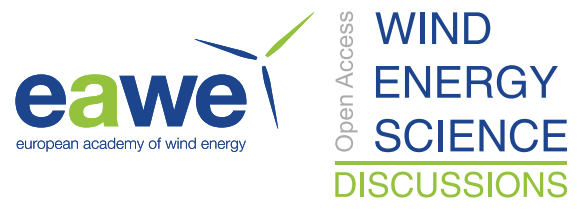

\section{Conclusions}

This work shows that the Dynamic Flow Predictor, a dynamic, linear, engineering model, can provide accurate estimates and predictions of wind turbine rotor effective wind speed and power in SimWindFarm. Wind speed is estimated with a RMS error ranging between $0.6 \%$ and $3.5 \%$. Wind speed predictions can be provided with an error of less than $4 \%$ over a time horizon of $55 \mathrm{~min}$. Over the same $5 \mathrm{~min}$ time horizon, turbine available power is predicted with an error of less than $15 \%$. In addition to the observed accuracy of the model, the model is computationally less expensive than comparable, dynamic two-dimensional CFD models. It is estimated that the Dynamic Flow Predictor requires only 5\% of the states of a comparable 2D CFD model. The choice of a linear state space modelling approach enables the Dynamic Flow Predictor's application in a wide range of control areas. Currently envisioned application areas are wind farm control, wind turbine control and as virtual wind turbine sensor.

Competing interests. There is no competing interests.

Acknowledgements. This work is funded by the CONCERT project, which is funded by Energinet.dk under the Public Service Obligation scheme (ForskEL 12396) with project partners Vattenfall R\&D and Siemens Wind Power. Siemens Wind Power and Vattenfall R\&D are gratefully acknowledged for their fruitful discussions. 
Wind Energ. Sci. Discuss., https://doi.org/10.5194/wes-2018-29

Manuscript under review for journal Wind Energ. Sci.

Discussion started: 14 May 2018

(c) Author(s) 2018. CC BY 4.0 License.

\section{References}

Boersma, S., Gebraad, P., Vali, M., Doekemeijer, B., and van Wingerden, J.: A Control-oriented Dynamic Wind Farm Flow Model: “WFSim”, Journal of Physics: Conference Series, 753, 032 005, 2016.

Crespo, A. and Hernández, J.: Turbulence Characteristics in Wind-turbine Wakes, Journal of Wind Engineering and Industrial Aerodynamics, 61, 71-85, 1996.

Frandsen, S., Barthelmie, R., Pryor, S., Rathmann, O., Larsen, S., and Hojstrup, J.: Analytical Modelling of Wind Speed Deficit in Large Offshore Wind Farms, Wind Energy, 9, 39-53, 2006.

Gebraad, P. M. O. and van Wingerden, J.-W.: A Control-Oriented Dynamic Model for Wakes in Wind Plants, Journal of Physics: Conference Series, 524, 012 186, 2014a.

10 Gebraad, P. M. O. and van Wingerden, J.-W.: Data-Driven Wind Plant Control, Ph.D. thesis, 2014 b.

Göçmen, T., Giebel, G., Sørensen, P. E., and Poulsen, N. K.: Possible Power Estimation of Down-Regulated Offshore Wind Power Plants., Ph.D. thesis, 2016.

Grunnet, J., Soltani, M., and Knudsen, T.: Aeolus Toolbox for Dynamics Wind Farm Model, Simulation and Control, in: European Wind Energy Conference, p. 10, 2010.

15 Grunnet, J., Soltani, M., and Knudsen, T.: SimWindFarm Official Website, http://www.ict-aeolus.eu/SimWindFarm/index.html, 2016.

Jonkman, J., Butterfield, S., Musial, W., and Scott, G.: Definition of a 5-MW Reference Wind Turbine for Offshore System Development, in: NREL/TP-500-38060, 2009.

Jung, J. and Broadwater, R. P.: Current Status and Future Advances for Wind Speed and Power Forecasting, Renewable and Sustainable Energy Reviews, 31, 762-777, 2014.

20 Kalman, R. E. and Bucy, R. S.: New Results in Linear Filtering and Prediction Theory, Journal of Basic Engineering, 83, $95,1961$.

Kazda, J., Göçmen, T., Giebel, G., and Cutululis, N.: Possible Improvements for Present Wind Farm Models Used in Optimal Wind Farm Controllers, in: Wind Integration Workshop, 2016a.

Kazda, J., Gogmen, T., Giebel, G., Courtney, M., and Cutululis, N.: Framework of Multi-objective Wind Farm Controller Applicable to Real Wind Farms, in: WindEurope Summit 2016, 2016 b.

Kazda, J., Merz, K., Tande, J. O., and Cutululis, N. A.: Mitigating Turbine Mechanical Loads Using Engineering Model Predictive Wind Farm Controller, in: IOP Conference Series - Journal of Physics - submitted, 2018.

Knudsen, T., Bak, T., and Soltani, M.: Prediction Models for Wind Speed at Turbine Locations in a Wind Farm, Wind Energy, 14, 877-894, 2011.

Machefaux, E., Larsen, G. C., Troldborg, N., Gaunaa, M., and Rettenmeier, A.: Empirical Modeling of Single-wake Advection and Expansion Using Full-scale Pulsed Lidar-based Measurements, Wind Energy, 18, 2085-2103, 2015.

Mikkelsen, T., Angelou, N., Hansen, K., Sjoholm, M., Harris, M., Slinger, C., Hadley, P., Scullion, R., Ellis, G., and Vives, G.: A Spinnerintegrated Wind Lidar for Enhanced Wind Turbine Control, Wind Energy, 16, 625-643, 2013.

Riverso, S., Mancini, S., Sarzo, F., and Ferrari-Trecate, G.: Model Predictive Controllers for Reduction of Mechanical Fatigue in Wind Farms, IEEE Transactions on Control Systems Technology, 25, 535-549, 2017.

35 Schlipf, D., Schlipf, D. J., and Kühn, M.: Nonlinear Model Predictive Control of Wind Turbines Using LIDAR, Wind Energy, 16, 1107-1129, 2013. 
Wind Energ. Sci. Discuss., https://doi.org/10.5194/wes-2018-29

Manuscript under review for journal Wind Energ. Sci.

Discussion started: 14 May 2018

(c) Author(s) 2018. CC BY 4.0 License.

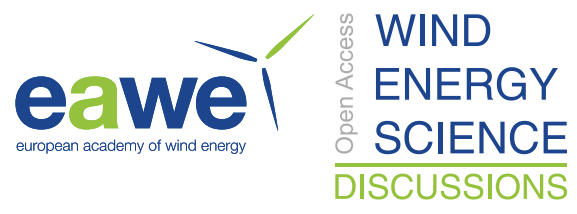

(c) (1)

Shapiro, C. R., Meyers, J., Meneveau, C., and Gayme, D. F.: Wind Farms Providing Secondary Frequency Regulation: Evaluating the Performance of Model-based Receding Horizon Control, pp. 11-24, 2018.

Soleimanzadeh, M., Wisniewski, R., and Brand, A.: State-space Representation of the Wind Flow Model in Wind Farms, Wind Energy, 17, 627-639, 2014.

5 Wang, J. and Hu, J.: A Robust Combination Approach for Short-term Wind Speed Forecasting and Analysis-Combination of the ARIMA (Autoregressive Integrated Moving Average), ELM (Extreme Learning Machine), SVM (Support Vector Machine) and LSSVM (Least Square SVM) Forecasts Using a GPR (Gaussian Process Regression) Model, Energy, 93, 41-56, 2015. 